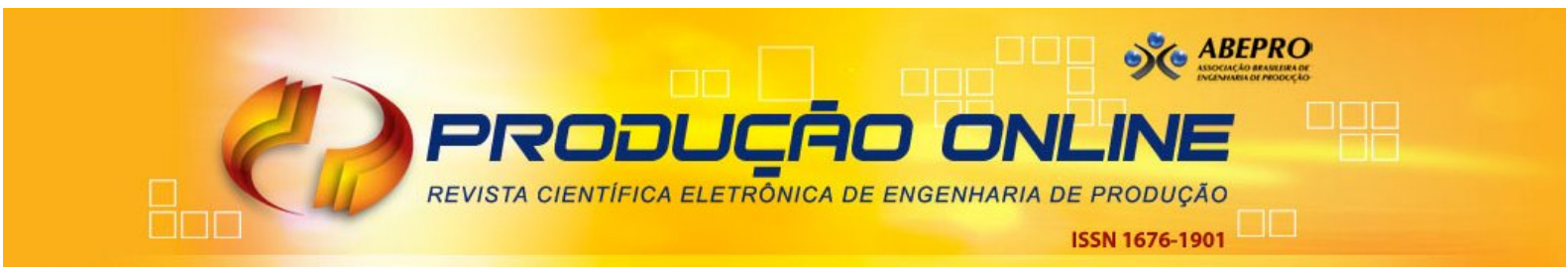

\title{
INOVAÇÃO NO PROJETO DE PRODUTO COMO FATOR PARA REDUÇÃO DE CUSTOS LOGÍSTICOS E DE PRODUÇÃO
}

\section{INNOVATION IN PRODUCT DESIGN AS A FACTOR FOR REDUCING LOGISTIC AND PRODUCTION COSTS}

\author{
Luciana Fighera Marzall ${ }^{*}$ E-mail: lucimarzall@gmail.com \\ Lucas Almeida dos Santos* E-mail: luksanttos@gmail.com \\ Leoni Pentiado Godoy* E-mail: leoni godoy@yahoo.com.br \\ *Universidade Federal de Santa Maria (UFSM), Santa Maria, RS
}

Resumo: A inovação tem sido considerada de fundamental importância para organizações que competem em ambientes dinâmicos, que em conjunto com o gerenciamento dos custos tem se demonstrado como uma estratégia organizacional que permite a empresa mensurar seus resultados e implementar medidas que impactam no desempenho da organização como um todo. O presente artigo, realizado numa indústria metal mecânico do ramo de engenharia de telecomunicações, tem como objetivo analisar a redução de custos, nos âmbitos logísticos e de matéria prima, por meio da inovação no projeto do produto, qual seja antenas/torres para redes de telefonia. Em termos metodológicos, este estudo se apresenta como uma pesquisa-ação de natureza quali-quantitativa, que a partir do enlace entre a teoria e prática permite uma intervenção dos pesquisadores no meio estudado. Como resultados, tem-se o desenvolvimento de um projeto inovador, que permitiu a redução dos custos de produção em $68 \%$ e logísticos em $32 \%$. Apesar da diminuição significativa dos custos, a qualidade dos produtos fabricados não decaiu e as necessidades dos clientes foram atendidas, tornando assim, a empresa mais competitiva frente aos concorrentes. Pouco presente na literatura, essa análise do impacto nos custos de logística e produção devido a melhorias no projeto, é a principal contribuição teórica deste artigo.

Palavras-chave: Custos Logísticos. Custos de Produção. Projeto. Inovação. Antenas de Telecomunicações.

\begin{abstract}
Innovation has been considered of fundamental importance for organizations competing in dynamic environments, which along with cost management has been shown as an organizational strategy that allows the company to measure its results and implement measures that impact on the organization's performance as a whole. This paper, carried out in a metal mechanical industry of a telecommunications engineering branch, aims to analyse cost reduction in logistics raw materials areas through innovation in the product design, which are antennas and towers for telephone networks. In terms of methodology, this study presents itself as a qualitative and quantitative researchaction, which from the link between theory and practice allows for intervention in the middle of the researchers studied. As a result, an innovative project was developed, which allowed for the reduction costs of production by $68 \%$ and logistics by $32 \%$. Despite the significant decrease in costs, the quality of manufactured products not declined and customer needs were met, thus making the company more competitive against competitors. Not widespread in the literature, this analysis of the impact on logistics and production costs due to improvements in the project is the main contribution theoretical of this paper.
\end{abstract}

Keywords: Logistics Costs. Production Costs. Design. Innovation. Telecommunications Antennas. 


\section{INTRODUÇÃo}

Atualmente as organizações enfrentam constantes desafios para que possam se manter atuantes e terem vantagens competitivas frente aos seus concorrentes, pois o mundo globalizado que caracteriza-se por alta concorrência, força de trabalho diversificada, mudando continuamente as necessidades dos clientes e novas mudanças tecnológicas, coloca as organizações em acirrada disputa entre si. A readaptação dos produtos com o intuito de reduzir custos, tem levado muitas empresas a repensarem suas práticas produtivas, criando novas alternativas que não só reduzam gastos, mas elevem sua rentabilidade e mantenha a mesma competitiva no atual cenário econômico.

Ao buscarem melhores condições de competitividade, as organizações necessitam de ferramentas e processos que Ihes permitam eliminar os desperdícios, resultando na sustentabilidade e continuidade de seus negócios no cenário em que estão inseridas. Indiferentemente do sistema produtivo, a busca pela melhoria das técnicas e procedimentos, bem como as alternativas que mensurem seu desempenho e elimine as perdas, devem estar inseridas em qualquer tipo de empresa, fazendo parte de seus processos de produção (DONADEL et al., 2007).

Com isso, a inovação tem sido considerada como o principal fator para o reforço da competitividade das empresas e está cada vez mais ganhando novas oportunidades no mercado e/ou nos esforços de gestão das corporações (OECD, 1991; TOMALA; SÉNÉCHAL, 2004; YANG; ZHANG e DING, 2015). Quando se fala em inovação, geralmente, liga-se o termo a um novo produto. Porém ela tem um sentido muito mais amplo e pode acontecer em vários âmbitos dentro de uma organização. A inovação pode ser aplicada aos produtos, serviços, processos, métodos, modelo de negócio, formas de conquistar clientes e em qualquer outro fator que venha a contribuir para melhorar as empresas e a sociedade (BRUCE e BIRCHALL, 2011).

Outro fator impactante nas atividades organizacionais é a logística, onde concepção de Nazário (2000), o transporte é uma das áreas de grande importância, representando cerca de $3 / 5$ dos gastos logísticos. Neste sentido, os gestores necessitam desenvolver conhecimentos na área de transportes para que se atinja a eficiência e eficácia na entrega de mercadorias para o cliente final. Conforme Ballou 
(2006), a área de transporte representa, dentre outros fatores, gastos que a grande maioria das empresas possui.

Assim, o gerenciamento dos custos como uma estratégia organizacional permite a empresa mensurar seus resultados e implementar medidas que impactam no desempenho da organização como um todo. Diante do exposto, o presente estudo realizado numa indústria metal mecânico do ramo de engenharia de telecomunicações da Região Sul do Brasil, tem como objetivo reduzir os custos, nos âmbitos logísticos e de produção, por meio da inovação do produto alvo desenvolvido pela organização, antenas/torres para redes de telefonia.

Neste contexto, o presente estudo justifica-se, primeiramente, pelo enlace entre teoria e prática, uma vez que permite a interação dos pesquisadores com a realização dos procedimentos empíricos abordados na estruturação e planejamento das etapas da pesquisa. Ademais, complementando o exposto, o referencial teórico descrito a seguir abordará os tópicos referentes à inovação, desenvolvimento de novos produtos e custos logísticos, servindo de embasamento na construção dos resultados.

\section{REFERENCIAL TEÓRICO}

Nesta seção serão abordados os seguintes tópicos: inovação, desenvolvimento de novos produtos e custos logísticos.

\subsection{Inovação}

Compreende-se que a inovação é o processo de transformar ideias em resultados, e como todo processo, envolve vários elementos que precisam ser administrados, dos quais se destaca a disponibilidade de recursos financeiros e produtivos. No Brasil há um grande número de empresas de pequeno porte com potencial inovador, mas com dificuldades de implantar suas ideias por limitações de recursos, sendo necessária a criação de tecnologias que consigam dar suporte ao seu processo de inovação (CORAL; OGLIARI e ABREU, 2009; PERSICO; MANCA e POZZI, 2014). 
A temática da inovação alterou radicalmente as discussões sobre grandes temas e questões para as empresas na atualidade. Há diversas pesquisas que abordam diferentes temas da área de negócios a partir da perspectiva dos impactos e da importância da inovação (GUIMARÃES; LARA e TRINDADE, 2015). Dentre esses temas, os estudos que apontam como a inovação tecnológica (de produto e processo) se insere na estratégia competitiva vêm crescendo consideravelmente na literatura (ZHANG; VONDEREMBSE e CAO, 2006; JIMÉNEZ, et al., 2011; MACHUCA, et al., 2011).

A inovação competitiva bem sucedida é muito mais que simplesmente ter boas ideias. Ela exige um processo bem estruturado, com o qual a empresa pode criar novos produtos mais competitivos, em um menor espaço de tempo, com o intuito de manter ou ampliar sua participação em mercado em constante evolução (ROZENFELD et al., 2006).

Em outras palavras, a inovação é a exploração comercial de ideias, sendo essencial que elas envolvam todos os aspectos concernentes à melhoria do desempenho da empresa e defendem que a mesma, genericamente, pode acontecer nos seguintes âmbitos (BRUCE e BIRCHALL, 2011): inovação de produto ou serviço (produtos ou serviços novos e aprimorados); inovação de processo (novas maneiras de produzir, fornecer ou fabricar); inovação de mercado (novos mercados ou novas maneiras de fornecer bens e serviços); e inovação do negócio (transformação comercial, inovação de modelo comercial e diversificação).

Entre as inovações tecnológicas podem ser distinguidos inovações de produto (novo conhecimento tecnológico é aplicado para projetar e desenvolver novos produtos ou produtos existentes, mas melhorou) e inovações de processo (novo conhecimento tecnológico utilizado na aplicação de novos processos de produção ou melhorar existente) (MINGUELA-RATA, et al. 2014). Para entrar nos mercados, os produtos tendem a ser mais apropriado do que inovações de processo quanto possível a responder rapidamente às necessidades dos clientes inovações, aumentar a qualidade e variedade de produtos e ganhar quota de mercado antes de concorrentes (NIETO e SANTAMARIA, 2010).

A tecnologia é muitas vezes vista, do ponto de vista da estratégia competitiva, como uma fonte de competências essenciais, ou seja, um meio para melhorar a qualidade dos produtos de uma empresa e/ou promoverem a redução do seu custo 
de produção ou como uma forma de desenvolver, fabricar e lançar novos produtos mais atraentes para os consumidores (MATSUI, 2002; JIMÉNEZ et al., 2011; MACHUCA et al., 2011; OKE, 2013).

Figura 1 - As quatros dimensões da inovação

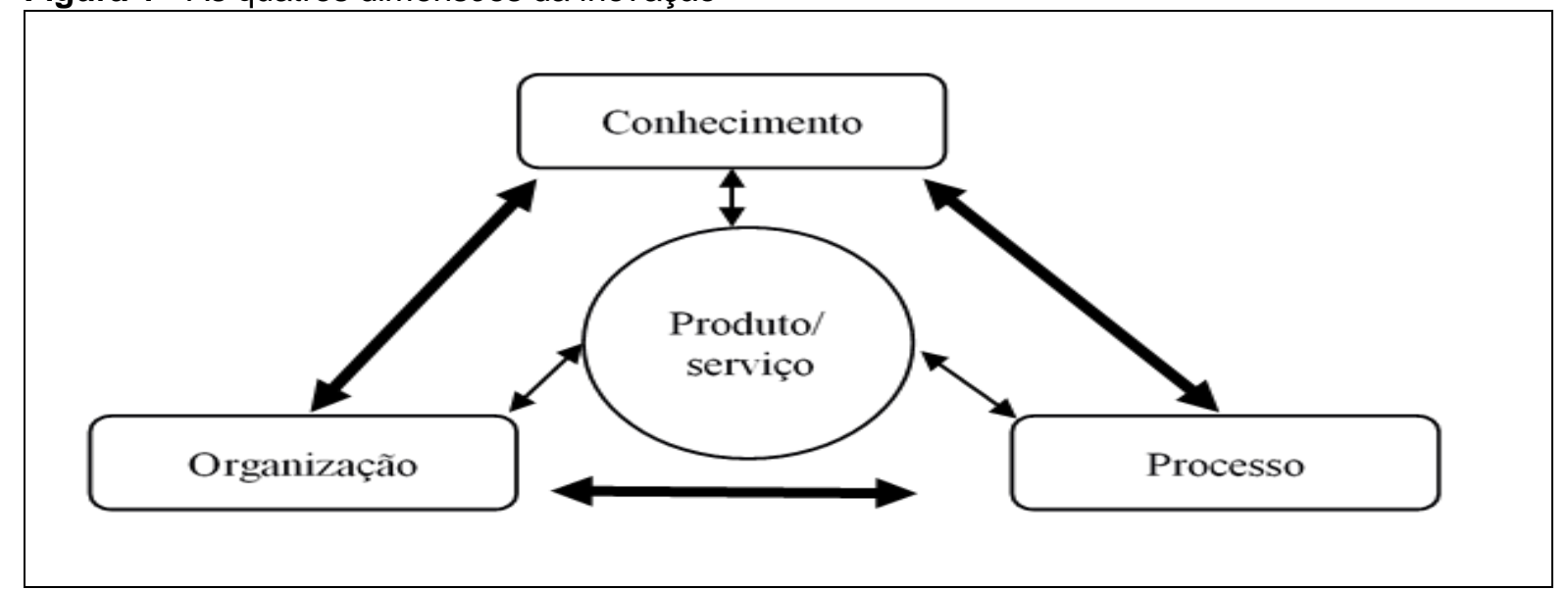

Fonte: Yang, Zhang e Ding (2015)

Entretanto, para acompanhar as rápidas mudanças nos mercados, tecnológicas, formas organizacionais e a capacidade de gerar e absorver inovações torna-se de extrema relevância a aquisição de novas capacitações e conhecimentos. Isso exprime em intensificar a capacidade das pessoas, empresas, países e regiões de aprender e modificar esse aprendizado em fator de competitividade para os mesmos.

Entre as inovações de produto, de acordo com seu grau de novidade, é possível distinguir vários tipos de inovações que abrangem produtos de modificações simples para inovações radicais; de modo que quanto maior o grau de originalidade, isto é, a mais extrema da inovação, maior o risco de mercado e incerteza (MINGUELA-RATA, et al. 2014). Nesse sentido, e sob o ponto de vista da empresa, podem-se distinguir as inovações incrementais (melhorias sobre os produtos existentes em empresas) e inovações radicais (quando o produto é inteiramente novo para a empresa).

\subsection{Desenvolvimento de Novos Produtos}

O desenvolvimento de novos produtos vem sendo considerado como um meio importante para a criação e sustentação da competitividade (TONI; MILAN e Revista Produção Online, Florianópolis, SC, v. 16, n. 1, p. 342-365, jan./mar. 2016. 
SCHULER, 2005). Para muitas indústrias, a realização de esforços nessa área é um fator estratégico e necessário para continuar atuando no mercado. A implementação de novos produtos sustenta a expectativa das empresas aumentarem sua participação de mercado e melhorar sua lucratividade e rentabilidade (KOTLER, 2000; PARASURAMAN; COLBY, 2002).

Como estratégia organizacional visando à redução de custos, o desenvolvimento de novo produto, ou até mesmo a reestruturação de um já existente, pode ser uma das saídas para que as organizações se mantenham competitivas no atual cenário econômico. As empresas que apostam numa estratégia de inovação através do desenvolvimento de novos produtos procuram o sucesso no mercado, uma utilização otimizada de recursos e a renovação da organização (GOMES et al., 2008).

Conforme Krishnan e Ulrich (2001) existem diferenças significativas, tanto na metodologia utilizada pelas empresas nos seus projetos de desenvolvimento, quanto na forma em que esses processos são executados. Os mesmos complementam indicando que essas diferenças também existem entre projetos dentro da mesma empresa. Isso realça a dificuldade de definição de uma melhor forma para gerenciar o desenvolvimento de produtos.

No que tange a vantagem competitiva, as empresas buscam constantemente uma base que garanta sua diferenciação em relação aos seus concorrentes. Outrora, bastava à organização aumentar sua capacidade produtiva, sem levar em consideração a qualidade dos produtos, custos e serviços diferenciados e a mesma era vista como competitiva. Porém, com a evolução do mercado, esse cenário foi se modificando, e as empresas passaram a dar importância aos aspectos abordados (BORGES e KLEIN, 2008; DORNIER et al. 2009).

O desenvolvimento de novos produtos também aumenta a competitividade das empresas e organizações através da redução de custos, do aumento da qualidade e muitas vezes da redução do tempo necessário para o produto chegar ao mercado. Os impactos que os projetos de desenvolvimento, efetivamente executados, podem ter na utilização de recursos, não só capitaliza esforços de investigação anteriores como alavanca e melhora recursos existentes. Adicionalmente, novos produtos e processos fornecem os meios para a organização 
superar debilidades do passado e estabelecer uma base mais forte de recursos para o futuro (BURGELMAN; MAIDIQUE e WHEELWRIGHT, 2001).

Em se tratando do processo inovativo, de acordo com Kotler (2000), a organização que não consegue gerar algum tipo de inovação pode estar correndo sérios riscos, já que os produtos são vulneráveis às mudanças das necessidades e do gosto dos clientes, a novas tecnologias, a menores ciclos de vida do produto e competitividade global.

Neste sentido, Vários fatores podem ser determinantes para o sucesso ou fracasso no ingresso de novos produtos no mercado (PAULA, et al., 2010). De acordo com Baxter (2000), tais fatores podem ser divididos em três categorias principais: (a) a forte orientação para o mercado; (b) o planejamento e a especificação prévios, tais como estudos de viabilidade técnica e econômica; (c) os fatores internos à empresa. Contudo, para o desenvolvimento de novos produtos ou adaptação dos já existentes, existem três domínios relevantes (EPPINGER e SALMINEN, 2001): produto, processo e organização. Em situações de desenvolvimento complexo cada um destes domínios é decomposto de modo a facilitar a gestão da complexidade.

Complementando o exposto, Toni, Milan e Schuler (2005) elucidam que não é somente a complexidade ou grau de planejamento do processo no desenvolvimento de novos produtos que define o sucesso de uma nova oferta. Existem outros fatores que precisam ser analisados à luz de cada mercado, de cada empresa e de cada novo produto, uma vez que, tanto empresas de grande porte quanto de pequeno porte podem usufruir dos benefícios da aplicação de um processo planejado de desenvolvimento.

\subsection{Custos Logísticos}

Com o aumento da competitividade entre empresas desenvolvedoras de produtos, os custos de projeto e de processos devem ser considerados antes mesmo que a produção comece, pois assim é possível perceber sua viabilidade. De acordo com Sani e Allahverdizadeh (2012) a competição e voz dos consumidores vêm imperando sobre o que toda companhia deveria realizar de melhorias nos seus 
processos. Isto tem sido alcançado principalmente através da redução de custos de seus projetos e processos de produção.

Quanto aos custos logísticos, tem-se um conceito mais complexo, pois não inclui apenas o conceito de contabilidade, mas enfatiza a identificação das ineficiências das operações com o objetivo de alcançar o controle dos custos logísticos. Dessa forma, a pesquisa sobre esse assunto engloba a mensuração e a gestão das atividades logísticas (ZOU, 2011).

Os custos logísticos são decorrência das operações logísticas da empresa: suprimentos, conversão física e distribuição. Essas operações consideradas de serviços são de grande importância para as empresas, pois agregam valor aos clientes. Sendo assim, o mau gerenciamento dos custos logísticos tem impacto direto nos resultados financeiros das organizações (CHING, 2009). Neste sentido, Nazário (2000) elucida que o alto gasto de custos com a logística pode representar o dobro ou o triplo do lucro de uma organização e que em alguns casos, este custo chega a $1 / 4$ da receita bruta, podendo ultrapassar o lucro operacional.

Para Zou (2011) e Carneiro et al. (2009) discutem que a base para a mensuração dos custos logísticos está relacionada às atividades que são desempenhadas. Não existe, no entanto, um consenso quanto às atividades contempladas pela logística em toda sua extensão, cabendo a cada autor sua própria consideração. Ilos (2009), por exemplo, considera que o custo logístico total é composto por quatro itens: transporte, armazenagem, estoque e administração. Engblom et al. (2012), por sua vez, considera as classificações de Naula et al. (2006) e Toyli et al. (2008), que afirmam que os custos logísticos são formados pelo transporte, armazenagem, manutenção de estoques, administração de estoques, embalagens e custos indiretos de logística.

Nesta perspectiva, aumento dos custos logísticos tem causado grande preocupação para as grandes empresas, pois a necessidade de fornecer a seus clientes um produto de qualidade, com segurança e rapidez tem feito da logística um grande diferencial de mercado. Sendo uma das maiores preocupações que a logística possa gerar resultados satisfatórios para a empresa e um diferencial de mercado entre os concorrentes (SANTOS e ZANIRATO, 2006).

O planejamento e controle de médio prazo estão preocupados com maiores detalhes, e em alguns casos, faz-se necessário replanejar. Em outras palavras, 
busca direcionar as etapas da programação e execução das atividades operacionais da empresa (SLACK, CHAMBERS e JOHNSTON, 2009), que o Planejamento Mestre da Produção (PMP), complementa Moreira (2008) é apropriado para avaliar as necessidades imediatas de capacidade produtiva, além disso, servirá para definir compras eventualmente necessárias e estabelecer prioridades entre os produtos da programação.

Em se tratando da logística como estratégia, Faria e Costa (2010), corroboram com a ideia de que a mesma reúne parâmetros necessários para atender os níveis de serviços exigidos pelos clientes enquanto os custos da cadeia de suprimentos são minimizados, uma vez que se torna possível a empresa maximizar seus lucros. Para isso, faz-se necessário conhecer e gerenciar todas as atividades envolvidas nos processos produtivos.

Em se tratando do custo de produção, Baykasoğlu e Kaplanoğlu et al. (2006) e Ma et al. (2011) afirmam que grande parte dos custos logísticos são indiretos, tornando-se adequado utilizar, por exemplo, o método ABC para sua mensuração. $\mathrm{Na}$ concepção de Nakagawa (2002), o método de custeio ABC tem como pressuposto que os recursos de uma empresa são consumidos por suas atividades e não pelos produtos que ela fabrica, e os produtos surgem como consequências das atividades consideradas estritamente necessárias para fabricá-los e/ou comercializá-los, e como forma de entender as necessidades, expectativas e anseios dos clientes. Assim a ideia básica deste procedimento é identificar os principais processos e atividades dentro de uma empresa, apurar os custos destas atividades, entendendo seu comportamento e, então, chegar aos custos dos produtos e serviços resultantes destes processos (BORNIA, 2009).

Outro fator mencionado pelos autores supracitados é quanto ao transporte e sua influencia na redução de custos, pois o mesmo está em todos os processos logísticos de uma empresa, seja no abastecimento, na produção, bem como na distribuição dos produtos. A escolha do tipo de transporte a ser utilizado em cada processo vai depender dos objetivos tratados pela empresa, seja o de fazer com que o produto chegue ao seu destino final sim qualquer avaria, cumprir os prazos previstos, entregar a mercadoria no local certo. A gestão do fator transporte permite que a empresa alcance um diferencial competitivo em reação aos seus concorrentes mediante uma correta utilização dos modos de transportes. 
Quanto ao gerenciamento dos custos com embalagens é de grande importância, pois o objetivo da logística é movimentar bens sem danificá-los. Logo, esse fator depende da embalagem escolhida e do tipo da mesma, beneficiando assim, o manuseio e movimentação. O custo da embalagem (BOWERSOX; CLOX e COOPER 2007), de qual for o tipo, impacta os custo de diversas formas: na identificação do produto, na rapidez a separação, nos custos de transportes, a armazenagem e manuseio e na qualidade do serviço oferecido ao cliente provocando um trade-off entre esses elementos.

\section{ASPECTOS METODOLÓGICOS}

O presente artigo foi elaborado a partir de um estudo realizado numa indústria metal mecânico atuante no ramo de engenharia de telecomunicações, localizada na região Sul do Brasil, com atuação no mercado nacional, e teve como objetivo a redução de custos, nos âmbitos logísticos e de matéria-prima, por meio da inovação do produto alvo desenvolvido pela organização, antenas/torres para redes de telefonia.

Ademais, o estudo foi constituído sendo utilizado o método da pesquisa-ação de natureza quanti-qualitativa, que consiste em uma pesquisa social com base empírica que é concebida e realizada em associação com uma ação ou com a resolução de um problema coletivo e no qual os pesquisadores e os participantes representativos da situação ou do problema estão envolvidos de caráter cooperativo ou participativo (CAUCHICK, 2012). Na Figura 2 é possível verificar as etapas desenvolvidas no presente estudo. 
Figura 2 - Delineamento da Pesquisa

Etapa 1 - Proposta para redução dos custos de produção e logística

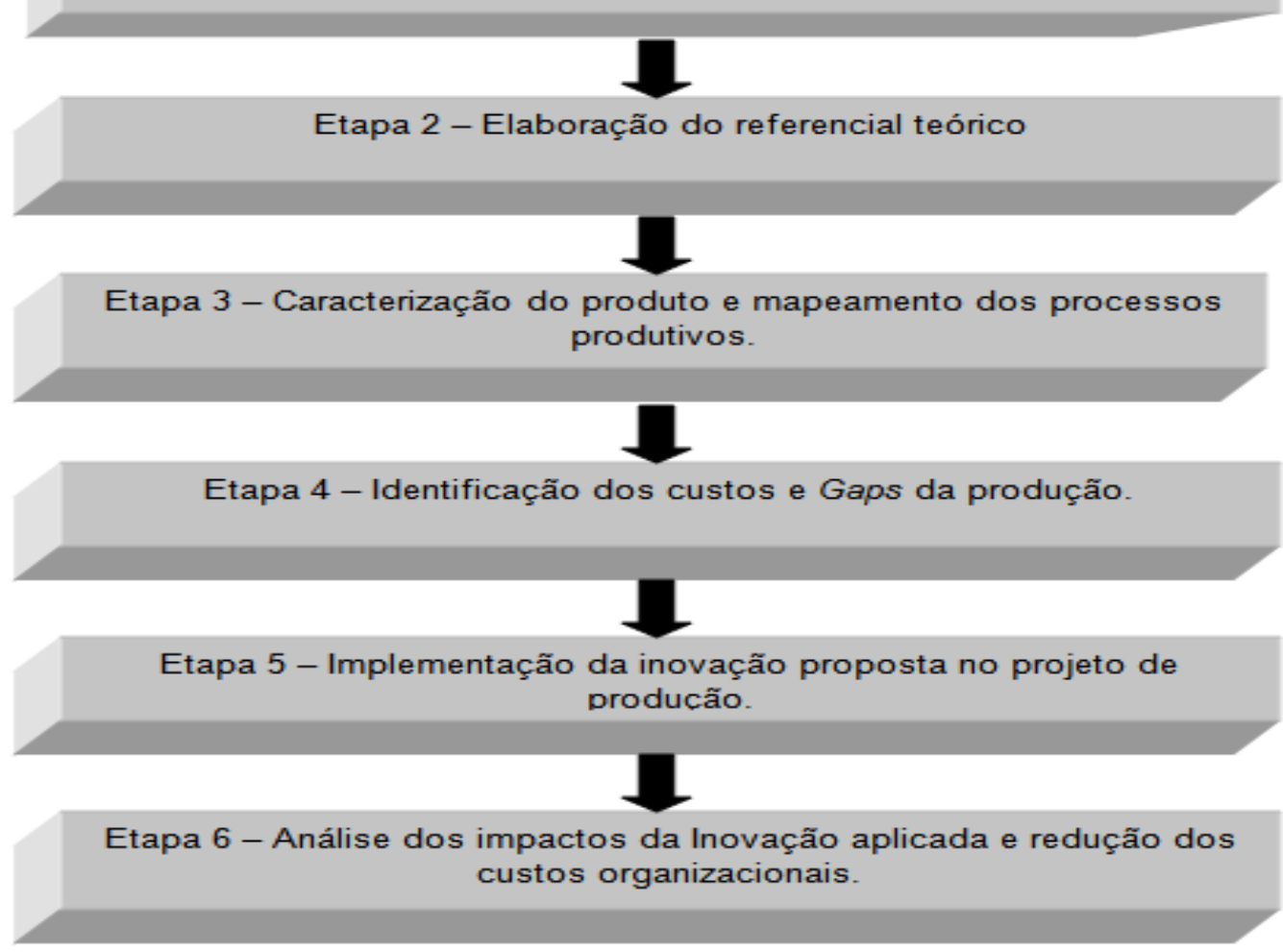

Fonte: Elaborado pelos autores

Por se tratar de uma pesquisa ação, salienta-se que a participação dos pesquisadores e gestores da empresa em foco ocorreu de forma conjunta em todas as etapas da pesquisa, pois houve uma produção cooperativa de conhecimentos sobre a realidade pesquisada, no qual a participação de todos os envolvidos pactuou desde a formulação dos objetivos até o desenvolvimento dos resultados. Ademais, a pesquisa possui caráter descritivo e observatório, no qual tornou-se necessário o entendimento do ambiente situacional da empresa em foco, que atrelado a necessidade de redução de custos oportunizaram o enlace entre a teoria e prática na busca por soluções do problema levantado.

\section{RESULTADOS E DISCUSSÕES}

O estudo foi desenvolvido em uma indústria instalada na região Sul do Brasil, onde fabrica antenas para telecomunicações e atende mercados específicos que demandam soluções profissionais em antenas e outros dispositivos passivos de 
rádio frequência $(R F)$, empregado no mercado de comunicação via wireless (transmissão de dados sem fio).

A organização em foco deste estudo foi fundada em 1991 e desde então passou por diversos desafios, necessitando reestruturar e inovar seus processos para atender a um mercado cada vez mais exigente. Atualmente, possui como clientes alguns dos mais importantes provedores de internet via rádio do Brasil, empresas petroleiras, operadoras de telefonia fixa e móvel, companhias de energia e empresas dos mais diversos setores econômicos entre as quais estão: ASGA, Motorola, CEEE e INPE (Instituto Nacional de Pesquisas Espaciais), OI, CLARO e VIVO.

Além disso, devido às mudanças tecnológicas no ramo em que atua, a organização precisou investir em P\&D (pesquisa e desenvolvimento), como forma de atender as demandas dos clientes, se manter competitiva e expandir seus negócios por meio da exportação. Outro marco importante na história da empresa se deu através da homologação de seus produtos pelas normas da ANATEL - Agência Nacional de Telecomunicações - aumentando assim, sua carteira de clientes e gerando patentes dos produtos desenvolvidos. Ademais, a empresa ainda atua na prestadora de serviços, fornecendo aplicações de corte a laser, gravação a laser e usinagem e dobra CNC em chapas metálicas.

\subsection{Descrição do Novo Produto}

Os resultados e discussões trazem informações referentes ao processo de inovação aplicado ao produto 4Y25015-17SG, antena denominada YAGI QUÁDRUPLA 244 - $262 \mathrm{MHz} 20,8 \mathrm{dBi}$, desenvolvido pela empresa foco. Este produto é composto de um arranjo de quatro antenas modelo YAGI que ficam dispostas paralelamente em uma torre de comunicações ligada a um rádio transmissor de sinal para a criação de um sinal de comunicação de telefonia. $O$ sistema estudado é denominado monocanal, que é composto por uma rádio comunicador e um arranjo de antenas dispostas em uma torre de comunicação que emite sinal para os receptores, conforme imagem da Figura 3. 
Figura 3 - Estrutura de um radioenlace de telefonia via Wireless

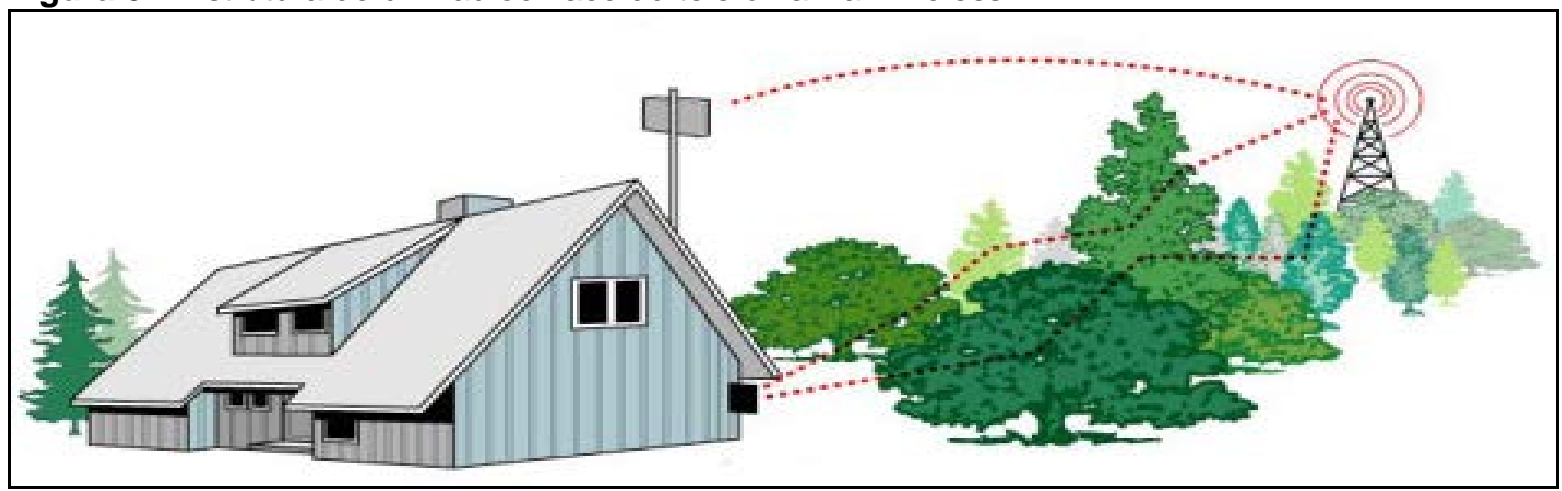

Fonte: Dados da pesquisa

O sistema monocanal emite sinal de uma estação central, onde fica a torre, as antenas e o rádio transmissor, e por uma estação assinante, que é o local onde está localizado o usuário do telefone que recebera o sinal via wireless (transmissão de dados ou voz sem fio). Estes sistemas são aplicados em locais de difícil acesso, como fazendas, onde não existe infraestrutura de cabeamento de telefonia convencional (via fios ou fibra óptica).

\subsection{Inovações do projeto}

A inovação desenvolvida no produto foco deste estudo, diz respeito às modificações de seu projeto com o intuito de reduzir o seu volume para transporte e reduzir custos de fabricação do mesmo. A inovação aqui tratada é proveniente da demanda de um dos principais clientes, que organização possui atualmente.

Segundo os clientes/gestores, a antena possui um desempenho superior às dos concorrentes, porém, devido ao aumento do custo de transporte, em função dos aumentos de preços dos combustíveis, fica praticamente inviável transportar estes itens da região Sul para as demais regiões do Brasil, onde se situam alguns clientes da empresa. Ou seja, o projeto original não mais corresponde às expectativas de custos o qual o cliente está disposto a pagar pela mercadoria.

Assim, estrategicamente, foi feito uma ação com os gestores do departamento de pesquisa e desenvolvimento da empresa foco deste estudo, colocando-se o problema encontrado e mobilizando a equipe na busca por ideias que viessem ao encontro dos seguintes objetivos propostos pela administração: melhorar o desempenho logístico reduzindo os custos de transportes, melhoria dos 
custos de fabricação e não comprometer o desempenho do produto e sua qualidade. Em síntese, propor a inovação do produto e a garantia de atendimento a todos os seus clientes.

Em se tratando das especificidades do produto, cada antena que compõe o arranjo do projeto inicial possuía 4,30 metros de comprimento após montada. Para o transporte, as antenas eram divididas em duas partes que eram unidas posteriormente por flanges parafusadas, cada uma com 2,15 de comprimento, ou seja, o produto era partido pela metade, conforme a Figura 4:

Figura 4 - Projeto inicial da Antena modelo YAGI

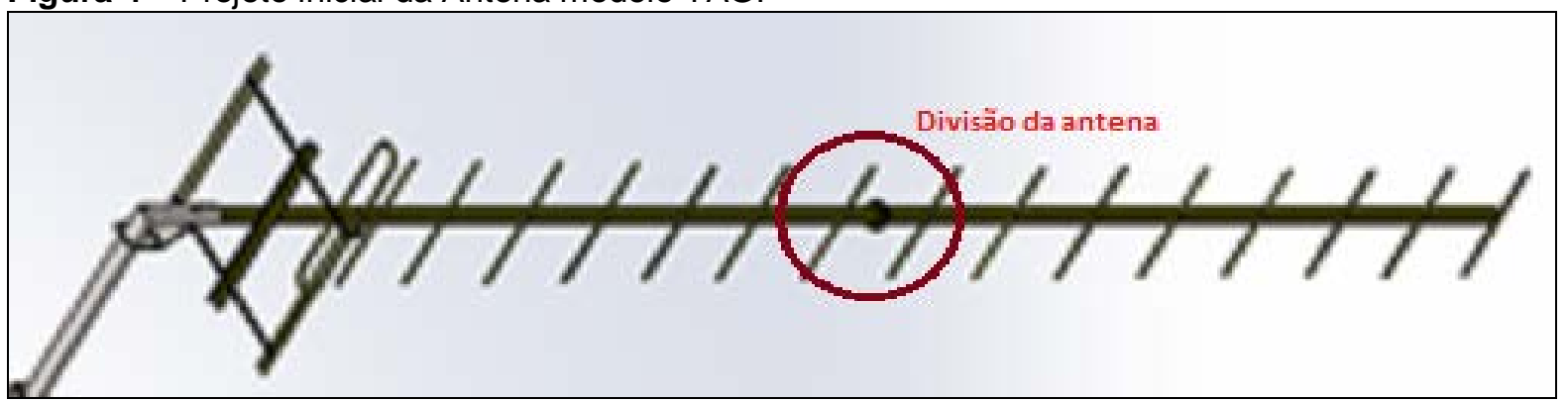

Fonte: Dados da pesquisa

Desta forma, o produto utilizava uma caixa de transporte de 2,20 metros, que após o processo inovativo ao qual foi submetida, a antena foi reduzida e seccionada em três partes de forma a não perder seu ganho de frequência, mas sim ser transportada em uma embalagem menor, conforme apresentado na Figura 5:

Figura 5 - Boom central da antena seccionado em três partes

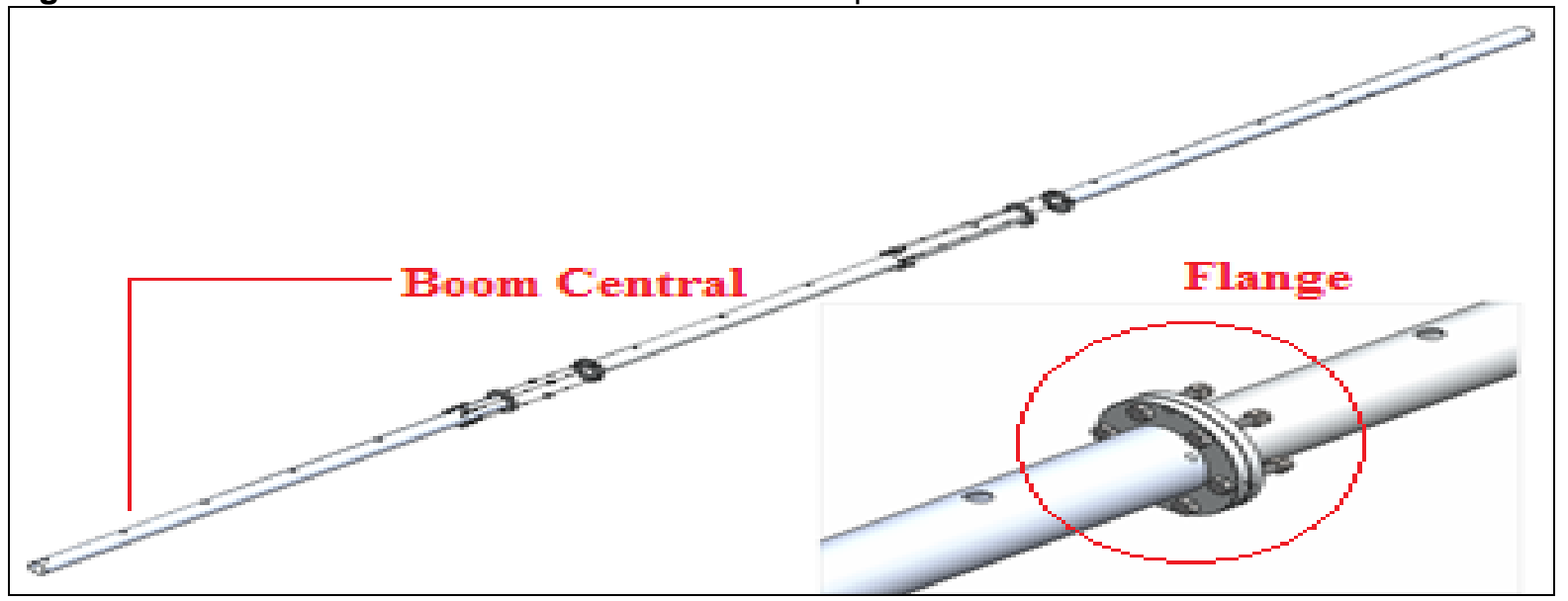

Fonte: Dados da pesquisa 
Analisando-se leigamente a situação, pode-se interpretar esta inovação como uma simples melhoria, porém a mudança do elemento central da antena assim como os elementos secundários altera totalmente o desempenho do projeto devido a interferência que as característica mecânicas do produto geram sobre o desempenho da mercadoria. A inserção de uma secção resultou no acoplamento de mais um flange na estrutura da antena e reposicionamento dos elementos secundários.

Desta forma, tornou-se necessário fazer um reposicionamento dos elementos secundários da antena e da grade refletora, onde forma feitas simulações da atuação do novo produto em campo e em softwares específicos de ondas eletromagnéticas para ajustar as novas disposições de suas partes. Também foi feita a troca da liga do alumínio utilizado no projeto para liga de alumínio naval, além de modificações nos suportes que interligam a antenas à torre de comunicação. Referente ao ganho eletromagnético da antena relativo às alterações efetuadas no projeto, analisa-se as informações sobre o desempenho do arranjo de antenas antes e depois das inovações implementadas conforme apresentado na Tabela 1:

Tabela 1 - Desempenho eletromagnético da antena antes e depois das inovações aplicadas

\begin{tabular}{|c|c|c|}
\hline Características Elétricas & Projeto Inicial & Projeto Inovador \\
\hline Tipo & 4Y25015-17SG & 4Y25015-17SG \\
\hline Faixa de Frequência & 244 a $262 \mathrm{MHz}$ & 244 a $270 \mathrm{MHz}$ \\
\hline Ganho Nominal & $20,8 \mathrm{dBi}$ & $20,8 \mathrm{dBi}$ \\
\hline Impedância Nominal & 50 Ohms & 50 Ohms \\
\hline R.O.E & $<1,3: 1$ & $<1,3: 1$ \\
\hline Polarização & Linear & Linear \\
\hline Relação Frente-Costa & $26 \mathrm{~dB}$ & $29 \mathrm{~dB}$ \\
\hline Isolação por Polarização Cruzada & $29 \mathrm{~dB}$ & $28 \mathrm{~dB}$ \\
\hline Feixe-3 dB@253 MHz - Plano E & $17^{\circ}$ & $17^{\circ}$ \\
\hline Feixe-3 dB@ $@ 253$ MHz - Plano H & $18^{\circ}$ & $18^{\circ}$ \\
\hline Potência Máxima de Entrada & $150 \mathrm{~W}$ & $150 \mathrm{~W}$ \\
\hline Máximo Lóbulo lateral & $-18 d B$ & $-17 d B$ \\
\hline Máximo Lóbulo lateral & $-27 d B$ & $-26 d B$ \\
\hline
\end{tabular}

Fonte: Dados da pesquisa 
Com isso, percebe-se que as alterações no desempenho não foram significativas, podendo-se analisar que a divisão da antena, a eliminação de processos e mudanças nos materiais e tratamentos aplicados não interferiram no desempenho do produto. Logo, as inovações aplicadas tornam-se válidas, uma vez que também foram levados em consideração o dispêndio de recursos financeiros aplicados em horas homem, simulações e prototipagens.

\subsection{Análise dos Impactos da Inovação de Produto Aplicada}

Devido à mudança de projeto foi possível fazer um (re) planejamento sobre os processos de produção das antenas, o que resultou na modificação do procedimento de fabricação de algumas partes deste produto, tornando o processo de fabricação mais produtivo. A ligação entre o boom central e os elementos da antena era fixada através de pontos de solda. Após as alterações executadas no projeto, estes pontos de solda foram substituídos por parafusos, o qual o cliente acopla os elementos à antena. Desta foram, do total de 22 pontos que a antena utiliza solda, 14 deles foram eliminados, representando uma redução de pontos de soldagem de aproximadamente $64 \%$.

A redução dos pontos de soldagem resultou em redução no tempo de produção do produto, pois o processo de acoplamento dos elementos passou a ser executado pelo cliente no momento da montagem do mesmo. Também se reduziu a utilização de varetas de solda, tornado o processo mais produtivo. Analisando estas reduções, estima-se que esta redução de 64\% de processo significa uma economia de duas horas de processo de soldagem por unidade produzida, além da matériaprima empregada, que finaliza na diminuição de $\mathrm{R} \$ 590$ reais de custos produção.

Em contrapartida, houve o aumento do uso de parafusos, porcas e arruelas na estrutura, empregadas para fixar os elementos anteriormente soldados, o que gerou um gasto de $\mathrm{R} \$ 210,00$ por unidade fabricada. Confrontando-se os valores, ainda obteve-se uma maior rentabilidade no projeto inovador em relação ao inicial, gerando uma economia de $\mathrm{R} \$ 380,00$ por unidade relativa a esta inovação de elementos desmontáveis.

A modificação da liga de alumínio utilizada pela liga naval, que é uma liga diferenciada que permite a exposição do produto aos mais diferentes climas e 
alterações de temperatura sem alterar sua estrutura física e química, resultou na eliminação do processo de pintura do produto, o que extinguiu o uso de tintas e solventes no produto. Logo, reduziu-se o custo do produto em $\mathrm{R} \$ 360,00$ reais em materiais aplicados e a diminuição de 3 horas do processo produtivo por unidade produzida. Calcula-se que a hora homem desta empresa esteja em torno de $\mathrm{R} \$$ 80,00 , assim termo uma redução de 240,00 de custo de horas homem trabalhada, aos quais foram eliminados juntamente com o processo de pintura.

Devido a esta inovação, reduzem-se também alguns custos indiretos de fabricação, como a utilização da câmera de pintura que não é acionada para a fabricação do produto inovador, diminuindo assim, o gasto de energia elétrica. Além de toda a economia gerada pela exclusão do tratamento de superfície da antena ainda existe o viés ambiental que está cada vez mais presente na realidade das empresas, o qual estas ações encaixam-se perfeitamente para os cumprimentos das premissas da sustentabilidade.

Conceitualmente, a embalagem possui múltiplas funções na cadeia de suprimentos. É um recipiente ou envoltura que armazena produtos temporariamente, individualmente ou agrupando em unidades, tendo como suas principais funções contenção, proteção, rateio, unitização, conveniência e comunicação do produto. A embalagem não só protege o produto a partir de influências externas, mas também pode proteger o ambiente interno que evolve o produto (HELLSTRÖM; SAGHIR, 2007; PÅLSSON et al., 2013).

Neste sentido, a modificação do projeto da antena gerou uma redução no volume da caixa a qual ela é transportada. Esta redução de volume resultou em uma menor quantidade de matéria prima para a construção da caixa a qual o produto é transportado. O projeto inicial utilizava $4,24 \mathrm{~m}^{2}$ de um material denominado OSB, material composto de restos de lascas de madeira para a confecção de uma caixa maciça que proteja totalmente o produto transportado. Na caixa do projeto inovador, a utilização de materiais ficou por volta de $1,36 \mathrm{~m}^{2}$ de material, resultado em uma redução de $68 \%$ no emprego de matéria prima para embalagem do produto, conforme Tabela 2. 
Tabela 2 - Comparativo da quantidade de matéria-prima

\begin{tabular}{|c|c|}
\hline \multicolumn{2}{|c|}{ Utilização de materiais na embalagem - OSB da caixa $\left(\mathrm{m}^{2}\right)$} \\
\hline Projeto Antigo & 4,24 \\
\hline Projeto Novo & 1,36 \\
\hline Redução & $68 \%$ \\
\hline
\end{tabular}

Fonte: Dados da pesquisa

Além da produção torna-se mais enxuta e consequentemente mais sustentável, houve uma redução do gasto com o material utilizado na caixa. O custo de produção da caixa reduziu em $68 \%$ o que tornou o produto mais lucrativo.

Tabela 3 - Custos dos materiais

\section{Custo dos Materiais Empregados na Embalagem}

Projeto Antigo

Projeto Novo
$\mathrm{R} \$ 67,84$

$\mathrm{R} \$ 21,76$

Fonte: Dados da pesquão $68 \%$

Assim, o OSB é adquirido em média pelo valor de $\mathrm{R} \$ 16,00$ o metro quadrado. Isto significa que os valores de materiais empregados para a construção de embalagens reduziram de $\mathrm{R} \$ 67,84$ para 21,76 por unidade transportada, reduzindo o custo geral da embalagem a uma taxa de $32 \%$ do valor antes pago por unidade, conforme Tabela 3.

\subsection{Redução de Custos de Logísticos}

No que se refere aos custos de transporte do produto, inicialmente calculouse o volume da caixa de transporte utilizada para o deslocamento da antena até o cliente. Levantaram-se informações sobre o projeto antigo e do projeto inovador para a comparação dos resultados. Os dados coletados demonstram que a caixa inicial tinha as medidas de 2,20 $\mathrm{m}$ de comprimento por 0,3m de altura e 0,7 $\mathrm{m}$ de largura. No projeto inovador a caixa de transporte passou a medir 1,60 m de comprimento por $0,2 \mathrm{~m}$ de altura e largura, conforme Tabela 4. 
Tabela 4 - Comparativo entre os projetos, quanto aos custos de transportes

\begin{tabular}{lll}
\hline Fatores & Projeto inicial & Projeto Inovador \\
\hline Tamanho da embalagem $(\mathrm{m})$ & $2,20 \times 0,3 \times 0,7 \mathrm{~m}$ & $1,60 \times 0,2 \times 0,2 \mathrm{~m}$ \\
Cubagem $\left(\mathrm{m}^{3}\right)$ & $0,31 \mathrm{~m}^{3}$ & $0,06 \mathrm{~m}^{3}$ \\
Custo de Transporte (unitário) & $\mathrm{R} \$ 553,16$ & $\mathrm{R} \$ 146,69$ \\
\hline
\end{tabular}

Fonte: Dados da pesquisa

Comparando-se os dados apresentados na Tabela 4, calcula-se que houve uma redução no volume da caixa (cubagem) de aproximadamente 79\%. Para uma maior assertividade, formalizou-se uma simulação do custo do transporte como os dados dos dois projetos para a obtenção das cotações de frete. Os critérios utilizados para a simulação do transporte foi a escolha da transportadora mais utilizada pela empresa e a contabilização dos pedidos dos últimos seis meses, onde foi possível constatar que cerca de $65 \%$ dos produtos vendidos são destinados à região sudeste brasileira, especificamente para a cidade de Barueri, localizada no Estado de São Paulo. Tal local foi escolhido em função da demanda de produtos estarem em sua maioria localizada nesta região e também porque é a cidade onde está localizado o cliente que demandou a mudança do projeto.

Logo, as informações utilizadas para a cotação de frete são a cubagem da caixa de transporte, o peso da mercadoria e seu valor de venda declarado em nota fiscal do produto. Como o peso do produto e o seu valor de venda não foram alterados, a alteração do valor da cubagem afetou diretamente o custo do transporte que saiu do valor de $\mathrm{R} \$ 553,16$ de custo inicial para $R \$ 146,69$, representando uma redução de $73 \%$ no valor de transporte pago pelo cliente. Assim, a inovação de produto cumpriu com sua meta principal que era redução do custo de transporte e tendo o cliente satisfeito.

As medidas adotadas pela organização terão uma abrangência a todos os clientes, uma vez que, com esta estratégia inovadora será possível à organização se tornar cada vez mais competitiva no mercado, satisfazendo seus clientes, aumentando sua produtividade e diminuindo os custos e tendo a possibilidade de atingir novos mercados.

\section{CONSIDERAÇÕES FINAIS}

Para se manterem competitivas no mercado, as organizações necessitam Revista Produção Online, Florianópolis, SC, v. 16, n. 1, p. 342-365, jan./mar. 2016. 
inovar para atender seus clientes, reduzir os custos e desenvolver estratégias que permita aumentar sua produtividade e consequentemente seus lucros. O caso estudado neste trabalho reforçou a necessidade da inovação, que proposta pela organização em foco, alterou seu projeto piloto a fim de atender a demanda dos clientes, garantindo assim, não somente a satisfação de valores monetários, mas também a qualidade dos novos produtos ofertados.

Mediante a inovação implementada, percebeu-se uma redução nos custos, tanto de produção, quanto os logísticos, uma vez que, a partir da iniciativa dos gestores em propor novas ideias em cima das necessidades dos clientes, outros fatores foram percebidos e puderam ser melhoradas, gerando assim, mais economia para ambas as partes. Com isso, notou-se a diminuição das horas trabalhadas, redução de matéria-prima, redução das embalagens e economia com energia elétrica, ao que parece, individualmente, não representam valores expressivos, mas que se somado ao montante produzido retrata para a organização valores satisfatórios.

No que tange as mudanças propostas, isso só foi possível mediante a gestão da empresa estar voltada em atender as necessidades dos clientes, possibilitando assim, que a partir de procedimentos bem estruturados e corpo profissional qualificado os resultados foram além dos esperados. O enlace entre a teoria e prática foi fundamental para o desenvolvimento de um projeto inovador, pois é valido salientar, que inúmeros testes foram feitos e varias simulações experimentadas para que se chegasse a um produto aceitável.

Como sugestões para estudos futuros, devido à abrangência das mudanças dentro da organização, pode ser feita uma pesquisa acerca do processo de inovação, por meio do conhecimento dos colaboradores, bem como a influência da cultura organizacional neste processo. Outra sugestão seria analisar a relação entre as estratégias de produção no desempenho da competitividade organizacional, tendo como base a inovação no setor de atuação da empresa.

\section{REFERÊNCIAS}

BALLOU, R.H. Gerenciamento da cadeia de suprimentos/logística empresarial. Trad. de Raul Rubenich. 5. ed. Porto Alegre: Bookman, 2006. 
BAXTER, M. Projeto de produto: guia prático para o design de novos produtos. São Paulo, Edgard Blücher, 2000.

BAYKASOĞLU, A.; KAPLANOĞLU, V. Application of business process modeling and simulation to a logistics company. In: International Conference on Modelling and Simulation, 2006.

BORGES, M.L.; KLEIN, M.J. Do limão a limonada: a gestão da cadeia de suprimentos de uma empresa de frutas in natura. In: XXXII Encontro EnAMPAD...Anais, Rio de Janeiro, 2008.

BORNIA, A.C. Análise gerencial de custos: empresas modernas. Porto Alegre, Bookman, 2009.

BOWERSOX, D.; CLOSS, D.; COOPER M. Gestão Logística de Cadeia de Suprimentos, Bookman, 2006.

BRUCE, A.; BIRCHALL, D. Via expressa para o sucesso em inovação. Porto Alegre, Bookman, 2011.

BURGELMAN, R.A.; MAIDIQUE, M.A.; WHEELWRIGHT, S.C. Strategic management of technology and innovation. New York, McGraw-Hill, 2001.

CARNEIRO, C.; ASSUNÇÃO, D.; SANTOS, G.; NUNES, R.; FONSECA, R. A Contribuição das Ferramentas de Custeio Logístico para Tomada de Decisão nas Empresas: Estudo de Caso em Indústria Cerâmica. In: XXIX Encontro Nacional de Engenharia De Produção, Salvador, Enegep, 2009.

CAUCHICK, M.P.A. Metodologia de pesquisa em engenharia de produção e gestão de operações. Elsevier, Rio de Janeiro, 2012.

CHING, H. Gestão de Estoques na cadeia de logística integrada - Supply Chain. São Paulo, Atlas, 2009.

CORAL, E.; OGLIARI, A.; ABREU, A.F. (Organizadores). Gestão integrada da inovação: estratégia, organização e desenvolvimento de produtos. São Paulo, Atlas, 2009.

DONADEL, C.M.; CANASSA, E.M.; RODRIGUEZ, C.M.T. O uso da manutenção produtiva total (MPT) como ferramenta geradora de produtividade e agilidade para a logística enxuta. In: XXVII Encontro Nacional de Engenharia de Produção, Foz do Iguaçu, Enegep, 2007.

DORNIER, P.P. et al. Logística e operações globais. Trad. Arthur Itkagi Utiyama. São Paulo, Atlas, 2009.

ENGBLOM, J. et al. Multiple-method analysis of logistics costs. International Journal of Production Economics, v. 137, n. 1, p. 29-35, 2012.

http://dx.doi.org/10.1016/j.ijpe.2012.01.007

EPPINGER, S.D.; SALMINEN, V. Patterns of product development interactions.

International conference on engineering design. Glasgow, 2011. 
FARIA, A., COSTA, M. Gestão de Custos Logísticos. São Paulo, Atlas, 2010.

GOMES, J.F. et al. Manual de Gestão de Pessoas e do capital Humano. Lisboa, Edições Sílabo, 2008.

GUIMARÃES, M.R.N.; LARA, F.F.; TRINDADE, R.O.P. A relação entre a estratégia de produção e a prática da inovação tecnológica: um estudo em uma empresa produtora de alumínio. Revista de Administração Mackenzie, v. 16, n. 3, p. 109-135, 2015. http://dx.doi.org/10.1590/1678-69712015/administracao.v16n3p109-135

HELLSTRÖM, D.; SAGHIR, M. Packaging and Logistics Interactions in Retail Supply Chains. Packaging Technology and Science, v. 20, p.197-216, 2007.

http://dx.doi.org/10.1002/pts.754

ILOS. Panorama de Terceirização Logística no Brasil. Instituto de Logística e Supply Chain, 2009.

JIMÉNEZ, C.; GARRIDO-VEGA, P.; RÍOS, J.; GONZÁLEZ, S. Manufacturing strategytechnology relationship among auto suppliers. International Journal of Production Economics, v. 133, n. 2, p. 508-517, 2011. http://dx.doi.org/10.1016/j.ijpe.2011.04.011

KRISHNAN, V.; ULRICH, K.T. Product development decisions: a review of the literature. Management Science, v. 47, n. 1, p.1-21, 2001. http://dx.doi.org/10.1287/mnsc.47.1.1.10668

KOTLER, P. Administração em marketing. São Paulo, Afiliada, 2000.

MA, X.; LI, J.; YANG, B. Accounting analysis on activity cost in logistic enterprise. In: International Conference on Industrial Engineering and Engineering Management, IE\&EM), 2011. http://dx.doi.org/10.1109/icieem.2011.6035177

MACHUCA, J.; JIMÉNEZ, C.; GARRIDO-VEGA, P.; RÍOS, J. Do technology and manufacturing strategy links enhance operational performance? Empirical research in the auto supplier sector. International Journal of Production Economics, v. 133, n. 2, p. 541550, 2011. http://dx.doi.org/10.1016/j.ijpe.2010.12.010

MATSUI, Y. Contribution of manufacturing departments to technology development: na empirical analysis for machinery, electrical and electronics, and automobile plants in Japan. International Journal of Production Economics, v. 80, n. 2, p. 185-197, 2002. http://dx.doi.org/10.1016/S0925-5273(02)00317-1

MINGUELA-RATA, B.; FERNÁNDEZ-MENÉNDEZ J.; FOSSAS-OLALLA M.; LÓPEZSÁNCHEZ, J.I. Colaboración tecnológica con provedores en la innovación de productos: análisis de la industria manufacturera española. Innovar, v. 24, Bogotá, 2014.

MOREIRA, D. Administração da Produção e Operações. Cengage, Learning, 2008.

NAKAGAWA, M. ABC: Custeio Baseado em Atividades. São Paulo, Atlas, 2002.

NAZÁRIO, P. Importância de sistemas de informação para a competitividade logística. In: FLEURY, P. F.; WANKE, P.; FIGUEIREDO, K. F. (Org.). Logística empresarial: a perspectiva brasileira. São Paulo: Atlas, 2000. Cap. 9, p. 285 - 296. 
NAULA, T.; OJALA, L.; SOLAKIVI, T. Finland State of Logistics 2006. Ministry of Transport and Communications Finland, 2006.

NIETO, M.J.; SANTAMARÍA, L. The importance of diverse collaborative networks for the novelty of product innovation. Technovation, v. 27, p.367-377, 2007.

http://dx.doi.org/10.1016/j.technovation.2006.10.001

OECD. The nature of innovation and the evolution of the productive system, OECD, Paris, 1991.

OKE, A. Linking manufacturing flexibility to innovation performance in manufacturing plants. International Journal of Production Economics, v. 143, n. p. 242-247, 2013.

PÅLSSON, H.; FINNSGÅRD, C.; WÄNSTRÖM, C. Selection of Packaging Systems in Supply Chains from a Sustainability Perspective: The Case of Volvo. Packaging Technology and Science, v. 26, p. 289-310, 2013. http://dx.doi.org/10.1002/pts.1979

PARASURAMAN, A.; COLBY, C.L. Marketing para produtos inovadores. Porto Alegre, Bookman, 2002.

PAULA, L. C.; SILVA, J. T. M.; TEIXEIRA, L. A. A.; TADEU, H. F. B. Análise do fator risco no lançamento de novos produtos: o caso do setor de microcervejarias. Teoria e Evidência Econômica, v. 16, n. 34, p. 145-171, 2010.

PERSICO, D.; MANCA, S.; POZZI, F. Adapting the technology acceptance model to evaluate the innovative potential of e-learning systems. Computers in Human Behavior, $v$. 30, n. 1. p. 614-622, 2014. http://dx.doi.org/10.1016/j.chb.2013.07.045

ROZENFELD, H.; AMARAL, D.C.; FORCELLINI, F.A.; TOLEDO, J.C.; SILVA, S. L.; ALLIPRANDINI, D.H.; SCALICE, R.K. Desenvolvimento de produtos: uma referência para a melhoria do processo. São Paulo, Saraiva, 2006.

SANI, A.A.; ALLAHVERDIZADEH, M. Target and Kaizen Costing. World Academy of Science, Engineering and Technology, v. 62, n. 10, p. 49, 2012.

SANTOS, R., ZANIRATO G. Mensuração dos custos logísticos de acordo com o método de custeio ABC. In: XXVI Encontro Nacional de Engenharia de Produção, ENEGEP. São Paulo, 2006.

SLACK, N.; CHAMBERS, S.; JOHNSTON, R. 2009. Administração da Produção. São Paulo, Atlas, 2009.

TOMALA, F.; SÉNÉCHAL, O. 2004. Innovation management: a synthesis of academic and industrial points of view. International. Journal Project Management, v. 22, n. 1 p. 281-287, 2004. http://dx.doi.org/10.1016/j.ijproman.2003.06.003

TONI, D.; MILAN, G.S.; SCHULER, M. O desenvolvimento de novos produtos: um estudo exploratório ambientado em empresas de acessórios plásticos para móveis. Revista

Produção Online, v. 5, n. 2, p. 1-15, 2005. http://dx.doi.org/10.14488/1676-1901.v5i2.339

TOYLI, J.; HAKKINEN, L.; OJALA, L.; NAULA, T. Logistics and financial performance: an analysis of 424 Finnish small and medium-sized enterprises. International Journal of

Revista Produção Online, Florianópolis, SC, v. 16, n. 1, p. 342-365, jan./mar. 2016. 
Physical Distribution \& Logistics Management, v. 38, n. 1, p. 57-80, 2008. http://dx.doi.org/10.1108/09600030810857210

YANG, C.; ZHANG, Q.; DING, S. An evaluation method for innovation capability based on uncertain linguistic variables. Applied Mathematics and Computation, v. 256, n. 1, p. 160174, 2015. http://dx.doi.org/10.1016/j.amc.2014.12.154

ZHANG, Q.; VONDEREMBSE, M.; CAO, M. Achieving flexible manufacturing competence: the roles of advanced manufacturing technology and operations improvement practices. International Journal of Operations \& Production Management, v. 26, n. 6, p. 580-599, 2006. http://dx.doi.org/10.1108/01443570610666957

ZOU, Y. Study on logistics operation cost control Based on the DEA model. International Conference on Management Science and Industrial Engineering (MSIE), 2011.

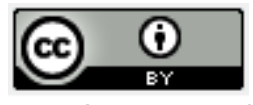

Artigo recebido em 12/09/2015 e aceito para publicação em 01/12/2015

DOI: http://dx.doi.org/ 10.14488/1676-1901.v16i1.2168 